This item was submitted to Loughborough's Research Repository by the author.

Items in Figshare are protected by copyright, with all rights reserved, unless otherwise indicated.

\title{
Comparison of flash boiling resistance of two injector designs and the consequences on downsized gasoline engine emissions
}

\section{PLEASE CITE THE PUBLISHED VERSION}

https://doi.org/10.1016/j.apenergy.2019.113735

\section{PUBLISHER}

Elsevier

\section{VERSION}

AM (Accepted Manuscript)

\section{PUBLISHER STATEMENT}

This paper was accepted for publication in the journal Applied Energy and the definitive published version is available at https://doi.org/10.1016/j.apenergy.2019.113735.

\section{LICENCE}

CC BY-NC-ND 4.0

\section{REPOSITORY RECORD}

Jiang, Changzhao, Matthew Parker, Daniel Butcher, Adrian Spencer, Colin Garner, and Jerome Helie. 2019. "Comparison of Flash Boiling Resistance of Two Injector Designs and the Consequences on Downsized Gasoline Engine Emissions”. Loughborough University. https://hdl.handle.net/2134/9938234.v1. 


\title{
Comparison of flash boiling resistance of two injector designs and the consequences on downsized gasoline engine emissions
}

\author{
Changzhao Jiang ${ }^{1}$, Matthew. C. Parker ${ }^{1}$, Daniel Butcher ${ }^{1}$, Adrian Spencer ${ }^{1}$, \\ Colin. P. Garner ${ }^{1}$, Jerome Helie ${ }^{2}$ \\ 1 Loughborough University, UK \\ 2 Continental Automotive SAS, Toulouse, France. \\ Corresponding Author: A.Spencer@lboro.ac.uk
}

\begin{abstract}
This paper presents a comparative study of two injectors designed for the same Gasoline Turbocharged Direct Injection engine, one featuring 5 holes and one with 6 holes. Hole diameter and circumferential spacing also differed between the two injectors in order to optimise targeting while maintaining flow rate and drop size distribution. By comparing the macroscopic spray characteristics of the two injectors, this study investigated possible design features which may better maintain a spray's intended morphology under severe flash boiling conditions. The sprays of each injector were firstly investigated by imaging in a quiescent pressure vessel before also being imaged in an endoscopically accessed version of the target 3-cylinder downsized engine to understand the impact of the spray morphology on performance and emissions. Near field images from the pressure vessel indicated that the 5-hole injector could tolerate a greater superheated degree before experiencing spray collapse, maintain its intended morphology better and exhibited a wider plume and shorter penetration length than the 6-hole injector for a given condition. Endoscopic images from the engine indicated that the spray area of the 5-hole injector was always wider under a range of start of injection timings, leading to a better air-fuel mixture and the observation of less diffusive combustion. The PN (particulate) emissions of the 5-hole injector was also consistently lower than the 6-hole injector under different injection timings due to better mixing and less piston impingement, whilst also being less sensitive to changes of injection timing due to its ability to maintain its spray morphology.
\end{abstract}

Key words: Flash boiling; Fuel injector; Spray collapse; Optical diagnostics; Endoscope imaging; PN emissions.

\section{Introduction}

Worldwide concern surrounding $\mathrm{CO}_{2}$ and other harmful emissions from combustion engines continues to drive the research and development of more efficient and less polluting forms of ground transportation. Major automotive market regions, such as Europe, North America and China, require $\mathrm{CO}_{2}$ emissions to reduce annually by $3-6 \%$ by 2025[1]. Increasing market penetration of electric vehicles are a part of this trend, but their relatively short range, charge times and the infrastructure required to produce a charging network are prohibitive to full adoption of electrification $[2,3]$ in the short term. Combustion engines are therefore still going to be a major part of ground transport strategy for a considerable time, at least as part of hybrid powertrain solutions [4]. In such hybrid systems the engine is likely to be downsized since, compared to a naturally aspirated engine, this strategy can alone reduce fuel consumption by around $18 \%$ under the New European Driving Cycle (NEDC) cycle[5]. This is because replacement of an existing engine with a smaller boosted engine forces the engine to operate in the higher efficiency region of the engine map. However, the smaller bore/stroke and its higher Break Mean Effective Pressure (BMEP) while operating bring about difficulties with PN and NOx emissions control. Thus, optimisation of the fuel 
spray and combustion processes of the downsized engine will therefore be a crucial part of automotive development in order to deal with those emissions.

At present, the majority of new gasoline engines are of direct fuel injection type (Gasoline Direct Injection, GDI), which offers improved transient response and cold start performance over port fuel injection (PFI) engines [6-8] as well as knock suppression and volumetric efficiency from the cooling effect of the fuel. These advantages combine to achieve a better overall engine performance (e.g. a reduction in fuel consumption). Quin et al [9] reviewed particulate formation in gasoline engines and considered many of the factors leading to particulate formation or oxidization. Formation of fuel films (or wall wetting) in any location are seen to be a key factor in particulate formation, whether this is induced by injection timing, fuel type or in cylinder conditions, as examples. The fuel spray of a GDI engine must be precisely controlled as fuel breakup and air charge utilisation must be balanced to minimise piston and cylinder wall impingement. Wu et al [10] used spray imaging to study how in cylinder conditions affected spray plume morphology. A six-hole injector under flash boiling conditions was seen to have a collapsed spray with the six jets combining into an injector axis aligned single jet with high penetration. Within a downsized engine flash boiling is likely to lead to increased risk of piston crown wetting. Having a good understanding of the spray formation characteristic is essential due to the increased risk of particulate formation. An understanding and choice of the injector geometries least susceptible to flash boiling would also allow an increased range of injection timings within the engine calibration process.

The aim of the in-cylinder GDI spray formation is to achieve as near to theoretical complete combustion as possible, whilst minimising many harmful emissions such as particulate matter. The highly variable and dynamic environment of the engine cylinder with changing engine speed and load conditions, and therefore temperature and air-flow structures, makes achieving this goal extremely challenging. Within this wide range of operating conditions, the fuel spray characteristics can vary significantly. However, Quin et al[9] state that high combustion efficiency in excess oxygen can lead to reduced particulate formation. This link between higher BSFC at high air-fuel ratio conditions and reduced particulate formation suggests that there are potential strategies to both improve fuel consumption and particulate emissions. Again, to realize this combination an understanding of the flash boiling effects will be important.

Flash boiling, which as described, has a significant effect on spray morphology and the resulting engine performance and emissions [11,12]. This phenomena occurs when the high-pressure fuel is injected into a low pressure and high temperature environment [12,13], a condition commonly encountered in GDI engines. For the fuel to fully mix with air, the injection event of a GDI engine is usually during the intake stroke, when the in-cylinder pressure is sub-atmospheric and the injector tip temperature (i.e. fuel temperature while injecting) is approximately $400 \mathrm{~K}$ to $530 \mathrm{~K}$; making the likelihood of flash boiling high.

Spray morphology changes due to injector coking and tip deposits have been seen to increase particulate formation and reduce engine efficiency[14]. In comparison to injector aging/coking, it has been found flash boiling produces more significant changes in plume morphology[15]. In further work[16] it was shown via in-cylinder imaging that diffusion flame from fuel-wetted surfaces increased in magnitude with increased wall wetting and indicated the mechanism through which particulates are formed. Bonatesta et al[17] showed spray-to-piston impingement increased as engine speed exceeded 3000rpm leading to high soot concentrations. These findings are further supported by Wang[18] who introduced spray impingement and wall film evaporation models into engine emissions software resulting in better performance of particulate number predictions. Khan et al[19] have also developed detailed models of spray formation under flash boiling processes to be included in CFD models, though limited experimental data exists to validate this under a wide range of conditions. 
Changing fuel types may also change atomisation processes leading to micro and macroscopic changes in spray and plume characteristics. Several studies have shown that fuel types do effect particulate emissions [20-22]. Some of the change will be due to fuel chemistry, but with different distillation curves there will also be changing susceptibility to flash boiling. There is not an intention of this work to look at additional parameters such as fuel type or injector aging, but it is worth noting that many of these factors will have effects that may affect flash boiling. In this sense the value of this work is to look at two injectors in detail to determine how their resistance to flash boiling compares. In what follows of this introductory section is a more detailed review of the flash boiling phenomena.

Kraemer et al. [23] computed the occurrence of flash boiling during normalised vehicle testing cycles, based upon typical fuel injection timing, engine cylinder pressure and fuel temperature for a for a mid-range, $1360 \mathrm{~kg}$ passenger vehicle fitted with a 4 cylinder, $1.41,91 \mathrm{~kW}$ engine [24]. They found that $95 \%$ of the test duration of the NEDC cycle and $99 \%$ of the test duration of the Real Driving Emissions (RDE) were affected by fuel superheating. Under extreme flash boiling conditions, the multi-jet GDI injector spray morphology can be significantly influenced by jet-to-jet interaction which can eventually lead to a full collapse of the jets towards the spray centre. Such a spray collapse reduces the spray angle [25], leading to less utilisation of the available air for mixing. It can also increase the spray penetration [26-28], leading to greater levels of piston and combustion chamber wall impingement. Both scenarios can potentially increase levels of both particulate and gaseous emissions such as $\mathrm{CO}$ and $\mathrm{HC}[29,30]$.

Sher et al. [12] summarises the mechanisms of flash boiling. The process is divided into three stages: bubble nucleation, bubble growth/expansion and the two-phase flow stages. Each of these stages impacts the development and final characteristics of the spray. To better understand the flash boiling phenomenon, significant research effort [31,32] has focused on the impact of temperature, pressure, super-heated value and pressure ratio between ambient and saturation pressure. These studies increase understanding on how in-cylinder conditions impact the spray flash boiling phenomenon.

Guo et al. [33] studied flash boiling using a single hole GDI injector. They found out that even under a severe flash boiling condition (superheat degree of $S D=60.23 \mathrm{~K}$ ), their single hole injector spray always exhibited external flash boiling (bubbles grow after exiting the nozzle). Comparing their results to literature, they found that with different hole geometry, internal flash boiling was generally observed under low SD values. Wu et al. $[10,34,35]$ investigated internal flash boiling and it was found that under flash boiling conditions bubbles already exist inside the nozzle hole and they mainly grow along the nozzle wall. It was concluded that injector nozzle geometry was impacting the flash boiling in the form of internal bubble generation and external nozzle fuel boiling. It was reported in Wang et al.'s work [36] that cavitation can promote the flash boiling by supplying vapor bubbles inside the nozzle, highlighting the importance of the nozzle shape when designing an injector.

Plume interaction was found to be an important factor for spray morphology change under flash boiling conditions $[37,38]$. Interaction between adjacent plumes generates a low-pressure zone in the spray centre which could lead to deformation of the plumes towards this region and eventually lead to spray collapse. It was also suggested that nozzle configuration was the key factor influencing plume to plume interaction.

As one may expect, flash boiling is impacted by injection strategy. Chan et al. [39] studied the impact of injection pressure on flash boiling, observing that high injection pressure could overcome the collapsing transition of flash boiling. Wang et al. $[40,41]$ reported that split injection strategy can reduce the penetration length of the spray therefore reducing the possibility of spray impingement. 
In conclusion, in order to reduce vehicle $\mathrm{CO}_{2}$ emissions, the current trend in the automotive industry is to use downsized engines in hybrid vehicles. The utilization of a GDI system in downsized engines highlights the importance of the spray pattern control especially under flash boiling conditions. From the literature, it is found that the tendency of a spray to flash boil is determined by fuel properties and the in-cylinder conditions; primarily temperature and pressure. However, the intensity of flash boiling is much more complex, depending on factors such as injection timing, temperature and pressure, nozzle length and diameter, cavitation inside the nozzle and plume to plume interaction. In order to reduce engine tailpipe out emissions, especially the particulate emissions, it is desirable minimise flash boiling due to its detrimental effects on spray morphology. This work explores an injector design which can increase the resistance to flash boiling and spray morphology change. It examines the spray characteristics of a 5-hole injector and a 6-hole injector under flash boiling conditions. Compared to the conventional 6-hole injector, the 5-hole injector nozzle holes are bigger in diameter and are further apart from each other. Through optical investigation on a spray characterisation rig and in a 3-cylinder downsized endoscopic engine, resistance of those two injectors to spray collapse is compared. The consequential impact of their spray characteristics on engine performance and engine emissions ( $\mathrm{NO}_{x}$ and $\left.\mathrm{PN}\right)$ is also studied.

\section{Methodology}

In this study a methodology for comparing the fuel spray behaviours of two candidate injectors for deployment in a newly developed Gasoline Turbocharged Direct Injection (GTDI) engine is presented. The data gathered alongside simulation data helped inform the choice of production injector. The study combined visualisation and optical measurements of the sprays with measured engine performance and emissions data, focussing on the performance of the injectors under flash boiling conditions. The two injectors were named five hole $(5 \mathrm{H})$ and six hole $(6 \mathrm{H})$ in reference to the number of holes they featured but they also featured different hole angular and distance separation as well hole diameters.

The optical investigation was made using a spray characterisation rig described in detail in references such as [42] and an endoscopically accessed Gasoline Turbo-charged Direct Injection (GTDI) engine, operated on a transient dynamometer. The characterisation rig was used to perform back-lit imaging of both near and far-field fuel spray characteristics under a range of simulated incylinder conditions. The endoscopically accessed engine was used to gain simultaneous high-speed images of fuel spray and combustion events alongside emissions measurements, in order to understand the relationship between fuel spray behaviour and engine performance.

\subsection{Spray characterisation imaging}

All spray imaging tests, including the far field spray morphology study, the near field spray study, and the interstitial plume study, were conducted in a constant volume chamber configured as Figure 1. The injectors were attached to a pressure-controlled vessel which featured quartz windows on three sides to provide optical access for both illumination and imaging. Illumination of the spray was provided by a Xenon flash panel configured behind the spray to provide shadow imagery. The camera used in this study was a 12-bit PCO CCD camera (1280 by 1024 pixels resolution), viewing the spray between it and the Xenon panel. Two lenses were used for the different tests presented here: a Nikkor $35 \mathrm{~mm} \mathrm{f} / 2$ for far-field imaging and LaVision $12 \mathrm{X}$ telecentric zoom lens systems for high magnification near-field imaging. A pulse timing box was used to control the pulse width of the injection signal and the timing of the xenon flash panel and the camera relative to the start of the injection signal. This allowed images to be captured at different stages of the fuel spray development. In order to freeze the spray motion, the image exposure time was fixed at $0.5 \mu \mathrm{s}$. The 
images were acquired using PCO CamWare software. A similar set up could be found in literature[25]. For the purposes of this study, the vessel temperature was controlled by a closed-loop controlled heated plate. The vessel pressure was controlled by a valve arrangement which could switch to introduce pressurised nitrogen into the vessel to achieve positive chamber pressures or to be evacuated by a vacuum pump to sub-atmospheric levels. Control of the system was via a National Instruments CompactDAQ controller, using LabVIEW code developed in-house.

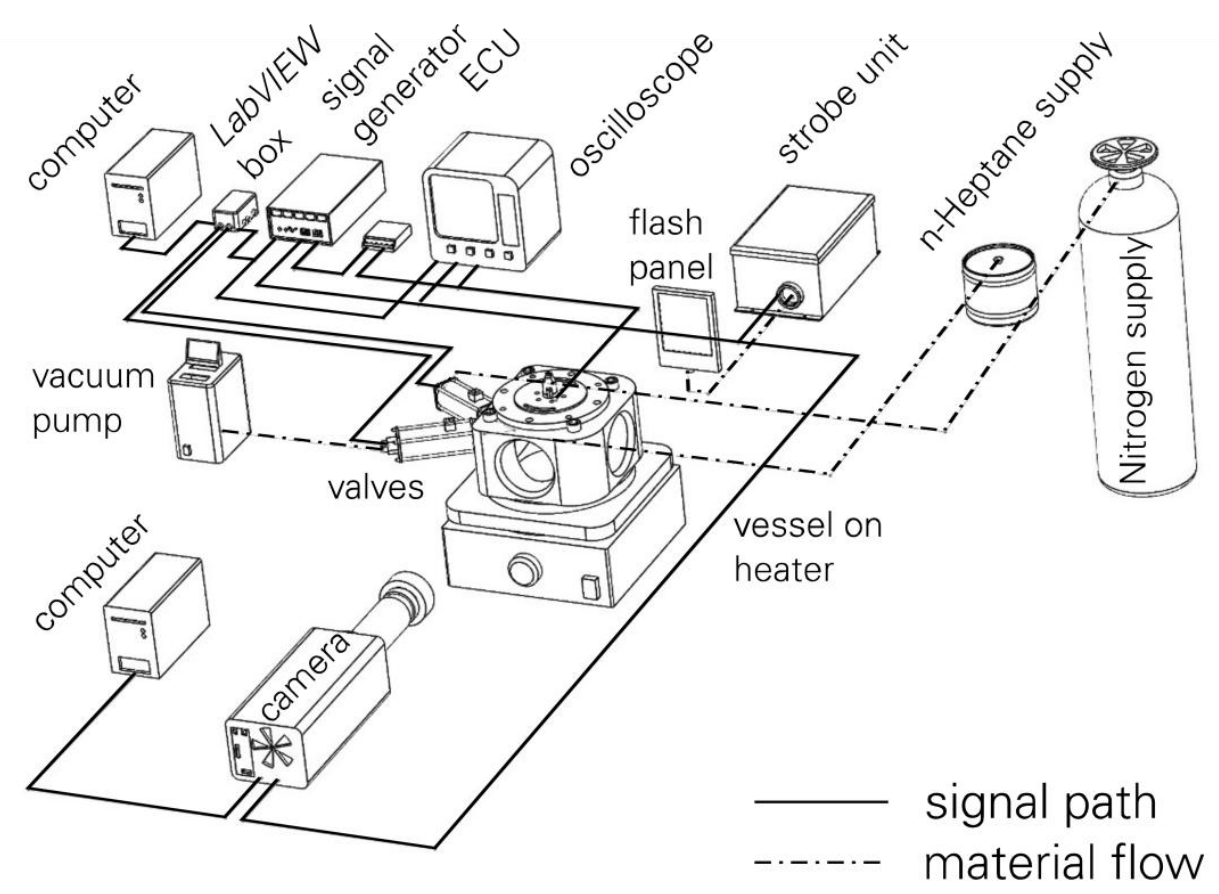

Figure 1 - Diagram illustrating the experimental configuration of injector spray imaging tests.

\subsection{Endoscopically accessible engine}

In addition to the measurements made on the spray characterisation rig, the injector designs were also tested in-engine using an endoscopically accessed version of the 1 litre in-line 3-cylinder GTDI engine whose specification is detailed in Table 1. The endoscopic access is illustrated in Figure 2, showing the routing of the access sleeve for insertion of the endoscope assembly running through the engine's timing cover and cylinder head. An identical access approach was also used to insert an quartz rod light guide into the engine, which allowed $10 \mathrm{kHz}$ pulsed illumination from a $\mathrm{Nd}$ :YAG laser to be delivered to the engine at $3 \mathrm{~mJ} /$ pulse (150 ns duration) to produce Mie scattered images of the fuel spray. A Photron AX200 high speed monochrome camera was used to capture images at a frame rate of $10,000 \mathrm{fps}$ and resolution of $512 \times 512$ pixels.

Table 1 - Experimental engine specification

\begin{tabular}{ll}
\hline Number of cylinders & 3 Cylinders \\
Engine type & 4-Stroke, Turbocharged Spark ignition \\
Valve arrangement & 2 intake, 2 exhaust per cylinder \\
Injection system & Multi-hole injector, Spray guided \\
Displacement per cylinder & $333 \mathrm{~cm}^{3}$ \\
\hline
\end{tabular}




\begin{tabular}{ll}
\hline Bore/Stroke & $71.9 \mathrm{~mm} / 82 \mathrm{~mm}$ \\
Compression ratio & 10.5 \\
Injection pressure & $20 \mathrm{MPa}$ \\
\hline
\end{tabular}

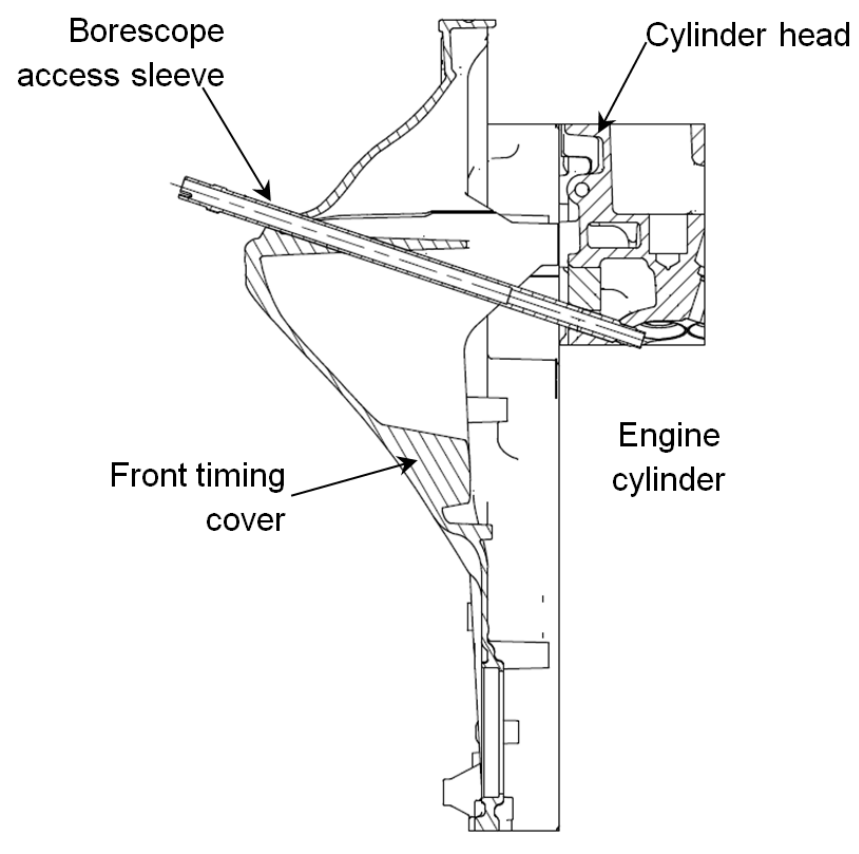

Figure 2 - The endoscope access into the 1 litre, inline 3-cylinder GTDI engine.

The endoscopically accessed GTDI engine was run on a dynamometer, allowing the in-cylinder spray morphology and combustion processes of the two injectors to be imaged, whilst the effect of the spray behaviour on engine performance and emissions could be measured. The dynamometer allowed control of the engine's speed and load whilst an Accurate Technologies Inc. (ATI) memory emulator module allowed parameters of the electronic control module (ECM) to be adjusted to set test conditions from a computer interface.

Engine performance was monitored by a National Instruments Compact RIO (cRIO) control and acquisition system, capturing low speed temperature and pressure data as well as high-speed crank angle aligned in-cylinder pressure data for combustion analysis. In addition, the system recorded emissions measurements from other analysers; $\mathrm{NO}_{x}$ emissions measurements from a Horiba MEXA7000 connected upstream of the catalyst. Particulate number (PN) emission measurements use a Cambustion DMS500, a differential mobility spectrometry device capable of measuring particles in the range of $5 \mathrm{~nm}-1 \mu \mathrm{m}$ via a heated sample line connected upstream of the catalyst. The sampling frequency of NOx is $10 \mathrm{~Hz}$ and the sampling frequency of DMS500 (PN emissions) is $1 \mathrm{~Hz}$. In total, emissions data is collected from 1500 complete (4-stroke) engine cycles, i.e. one minute at the tested conditions, in order to minimize the impact of cycle-to-cycle variation. Control of the camera and laser was achieved via the same cRIO system.

\subsection{Test Injectors and conditions}

The two candidate-injectors, whose specification is detailed in Table 2, were engineered alongside the engine development programme specifically for the engine's cylinder geometry. The hole lengths of the two injectors are the same although the hole diameters are different. Aside from hole number, there are other design differences, but the droplet size statistics of the injector were very similar, with a Sauter Mean Diameter, $D_{32}$, within $1 \%$. Phase Doppler Anemometry (PDA) 
measurement were available at the centre of all plumes of the two injectors at a vertical distance of $30 \mathrm{~mm}$ to injector tip. For brevity the PDA system and results are not described in detail here but interested readers can find full details in reference [43]. Based on the droplet size measurement from the PDA system, $D_{10}$ and $D_{32}$ were calculated from Equations 1 and 2:

$$
\begin{aligned}
& \mathrm{D}_{10}=\underline{\sum_{1}^{n}} \\
& \mathrm{D}_{32}=\square
\end{aligned}
$$

where $d_{i}$ is the diameter of individual droplets and $n$ is the number of validated droplets during the PDA measurement. A summary of the data is provided in Table 2.

\begin{tabular}{|c|c|c|}
\hline & 5-hole $(5 \mathrm{H})$ & 6-hole $(6 \mathrm{H})$ \\
\hline \multicolumn{3}{|l|}{ Hole arrangement } \\
\hline Hole diameter $(\mathrm{mm})$ & 0.18 & 0.15 \\
\hline Hole area $\left(\mathrm{mm}^{2}\right)$ & 0.127 & 0.106 \\
\hline Static flow (g/s @ $10 \mathrm{MPa})$ & 7.5 & 6.9 \\
\hline Distance between holes $(\mathrm{mm})$ & 0.89 & 0.74 \\
\hline Average droplet diameter $D_{10}(\mu \mathrm{m})$ & 6.14 & 6.59 \\
\hline Sauter Mean Diameter $D_{32}(\mu \mathrm{m})$ & 9.99 & 10.06 \\
\hline
\end{tabular}

Table 2 - Specification of the test injectors used in this study.

During engine tests, Euro 5 compliant gasoline was used, and the engine operated at $3000 \mathrm{rpm}$ speed and $85 \mathrm{Nm}$ load and using four individual injection timings; $330^{\circ}, 280^{\circ}, 230^{\circ}$ and $180^{\circ}$ Before Top Dead Centre (BTDC).

For the spray rig tests, $99 \%$ purity $n$-Heptane was used to match the simulations for validation, which typically use pure fuels. Additionally, for flash boiling tests, if a single component fuel is used, the super-heated degree may be accurately determined hence the flash boiling phenomenon of the two injectors may be better understood. N-heptane is commonly used by researchers in fuel spray studies, providing a good understanding of it could be found in literature which can be taken into consideration when carrying out our study.

The term Superheated Degree, SD is used throughout this paper. It is a term that compares the temperature of a fuel to its saturation temperature at a given pressure, as shown in Equation 3, where $T_{\text {fuel }}$ is the fuel temperature and $T_{\text {sat }}$ is the saturation temperature. The greater the positive value of this figure, the further the fuel is into the superheated vapour region.

$$
S D=T_{\text {fuel }}-T_{\text {sat }}
$$

\section{Results and Discussion}

The results that follow demonstrate a methodology for evaluating the performance of two candidate injectors designed for the same GTDI engine application, by using imaging methods to complement measured engine performance data. The approach used was to first gain an understanding of the injector's spray performance on the spray characterisation rig, initially at a macroscopic level and 
then at a microscopic level. The same injectors were then run in an endoscopically accessed version of the final engine, where their spray morphology and the resulting combustion could be imaged and ultimately compared with the engine performance.

\subsection{Macroscopic characteristics of the two injectors}

A starting point for gaining understanding of the injector behaviour was to study the macroscopic spray morphology on using the spray characterisation rig described previously, using $n$-heptane. This study obtains sequences of backlit spray images captured at several defined points of the injection event and at a range of environmental conditions representative of in-cylinder pressure and temperature, to simulate on engine-operation.

Spray morphologies for the $5 \mathrm{H}$ and $6 \mathrm{H}$ injectors captured at $0.7 \mathrm{~ms}$ after the start of injection (ASOI) are shown in the first two columns of Figure 3 and an overlaid copy of these in the third column; highlighting the differences between the two morphologies. The rows of Figure 3 denote four individual test conditions that were used to encompass fully formed through to fully collapsed sprays; the interim conditions illustrate a spray at the early stage of collapse and one showing significant, yet not complete collapse.

At the first reported test condition in Figure $3(296 \mathrm{~K}, 0.127 \mathrm{MPa})$ the superheated degree SD was negative, hence the $n$-Heptane remained in the liquid phase and as a result the spray was well formed and delivered in distinct plumes with sharp noses. At the second condition (359 K, 0.047 $\mathrm{MPa}$ ), the environment conditions meant that the $\mathrm{n}$-Heptane was in the gas phase, although still relatively close to the gas vapour line, with $S D=11.6 \mathrm{~K}$; as a result the spray plumes of both injectors were still distinct but noticeably wider with blunter leading edge profiles. As the SD was increased through the subsequent two points, it was clear that the plume structure was less well defined at the third condition and the individual plume structures were completely collapsed into a central combined plume at the highest SD. When comparing the relative performance of the $5 \mathrm{H}$ and $6 \mathrm{H}$ at the third and fourth conditions, it could be seen that the $5 \mathrm{H}$ maintained a more defined structure at the third condition, showing less inward collapse of the plumes. This suggests that the $5 \mathrm{H}$ injector has a better resistance to spray collapse under flash-boiling conditions. 


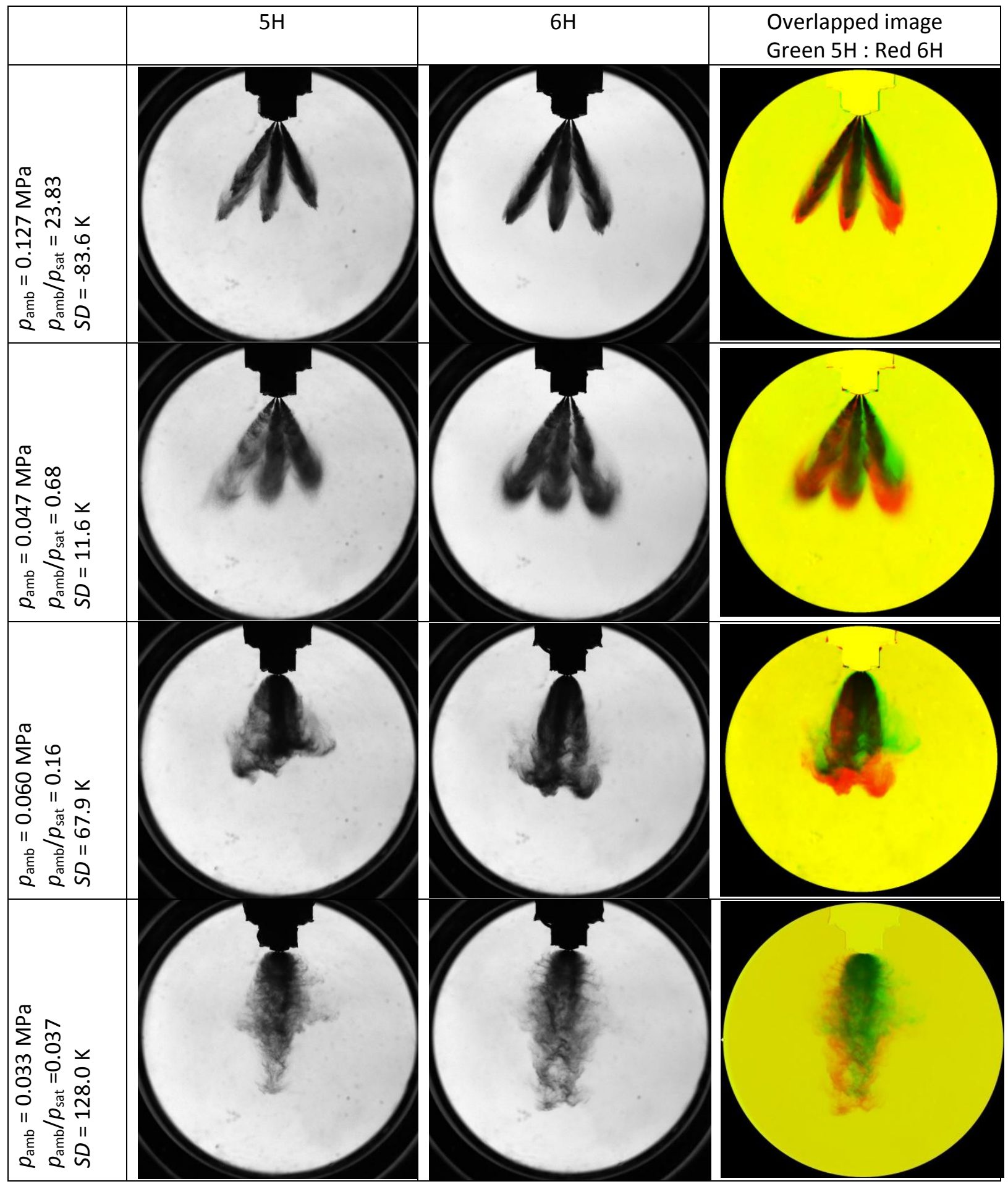

Figure 3 - Spray morphology under different pressure and temperature conditions (0.7 ms ASOI)

At the fourth condition, where the spray collapse was severe in both cases, the $5 \mathrm{H}$ injector showed slightly less collapse than the $6 \mathrm{H}$, further supporting the finding at the third condition. The key factor in spray collapse is the rate of flash boiling of the spray which is limited by the rate of heat transfer to the liquid fuel droplets from the ambient gas. Having more individual plumes will increase the plume surface area to fuel mass ratio. This increased surface area of shearing action (for given fuel mass) will generate a higher entrainment rate of the ambient gas into the plume, enhancing the net heat transfer rate from ambient gas to the liquid fuel. The additional hole, in moving from $5 \mathrm{H}$ to $6 \mathrm{H}$, also leads to a reduced pitch spacing. This will also lead to some enhancement of the rate of gas 
acceleration, hence lower pressure, in this interstitial region. Again, this increases the local SD, also potentially enhancing the rate of flash boiling as a secondary mechanism.

Penetration lengths of the plumes were measured over the range of image sets available (where only one time snapshot is illustrated in Figure 3 ) to understand the penetration of the injector plume tips with time ASOI over the four environment conditions tested. These results are plotted in Figure 4 with solid lines denoting $5 \mathrm{H}$ and dashed lines denoting $6 \mathrm{H}$. The penetration lengths plotted were averaged over 30 cycles to account for injector shot-to-shot variation and across the three plumes at the front of the images captured. The plume edges were determined using standard Matlab image processing toolbox functions. Edges were determined from binarized images, created using suitable intensity thresholds (examples of edges for in-cylinder plumes calculated this way are seen later in Figure 11). Using a backlit setup this method has been shown to reliably indicate the extent of liquid phase penetration into the pressure chamber. Here, penetration length is taken as the maximum vertical penetration of the plume from the injector tip (in what would be the direction perpendicular to the piston crown). When the sprays were formed or only slightly collapsed, for example in the case of SD value equal to $-83.6 \mathrm{~K}$ in Figure 3, penetration length was measured from all three visible plumes. When the sprays were fully collapsed, for example in the case of SD value equal to $128 \mathrm{~K}$ in Figure 3, there was only one central plume, thus only the penetration length of this plume was considered and reported.

Figure 4 shows the expected trend that as vessel pressure is reduced the plume penetration is increased due to the lower ambient gas density reducing the aerodynamic drag on the spray. As the $\mathrm{n}$-Heptane was subjected to an increasing SD value through the combination of environment temperature and pressure, the penetration length increased significantly, which is true for both injectors. At each condition the penetration length of the $6 \mathrm{H}$ injector was longer than the $5 \mathrm{H}$, by an average of $23 \%$, however this increase is more notable at the higher values of SD where the spray collapse occurs more fully for the $6 \mathrm{H}$ injector, as indicated qualitatively in Figure 3.

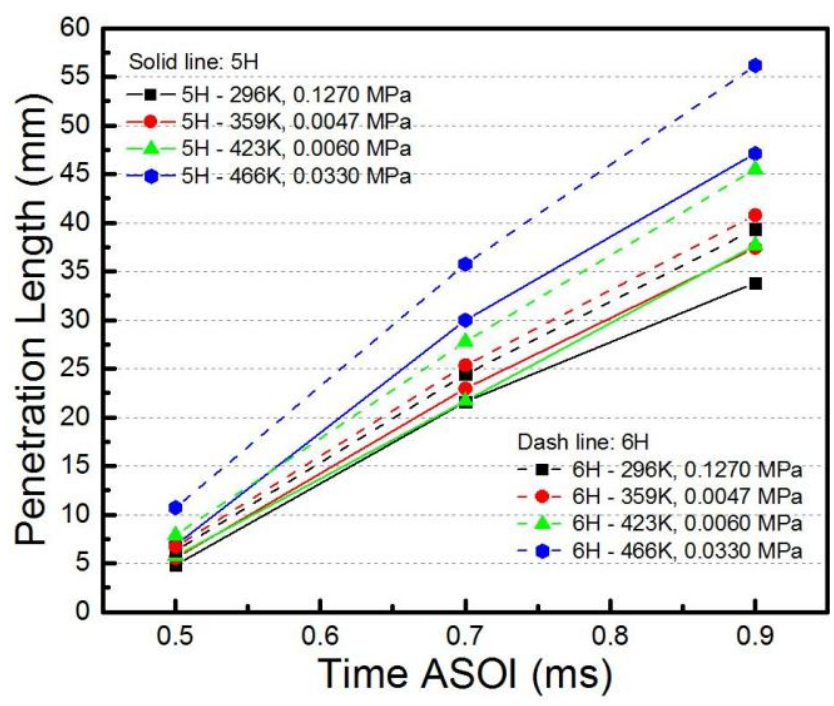

Figure 4 - Penetration length vs Time ASOI fo the $5 \mathrm{H}$ and $6 \mathrm{H}$ injectors under 4 test conditions.

\subsection{Near field imaging}

After determining that the $5 \mathrm{H}$ injector appeared to offer better resistance towards spray collapse in comparison to the $6 \mathrm{H}$ injector, the near field spray behaviour of each injector, close to the injector tip, was investigated to gain further insight into the way in which the spray plumes interacted with one another and affected the overall spray morphology. 


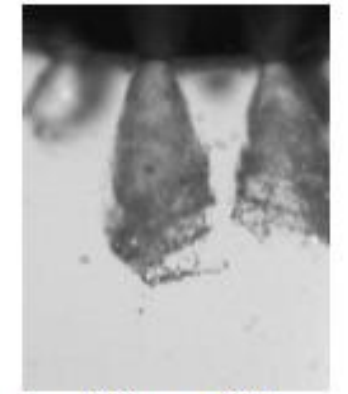

$t=430 \mu \mathrm{s}$ aeSOI,

$T=349 \mathrm{~K}$,

$p_{\mathrm{amb}}=0.047 \mathrm{MPa}$,

$p_{\text {amb }} / p_{\text {sat }}=0.95$,

$S D=1.6 \mathrm{~K}$

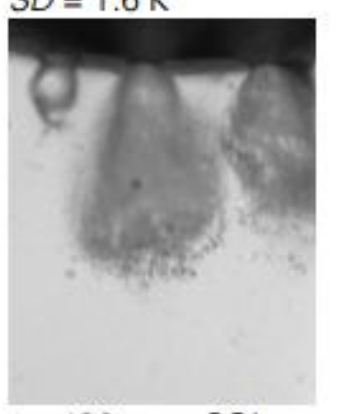

$t=430 \mu \mathrm{s}$ aeSOI,

$T=359 \mathrm{~K}$,

$p_{\text {amb }}=0.047 \mathrm{MPa}$,

$p_{\text {amb }} / p_{\text {sat }}=0.68$,

$S D=11.6 \mathrm{~K}$

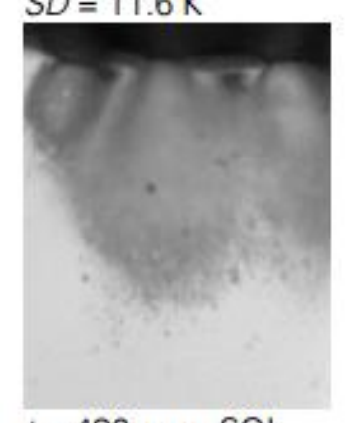

$t=430 \mu \mathrm{s}$ aeSOI,

$T=369 \mathrm{~K}$,

$p_{\mathrm{amb}}=0.047 \mathrm{MPa}$,

$p_{\text {amb }} / p_{\text {sat }}=0.5$,

$S D=21.6 \mathrm{~K}$

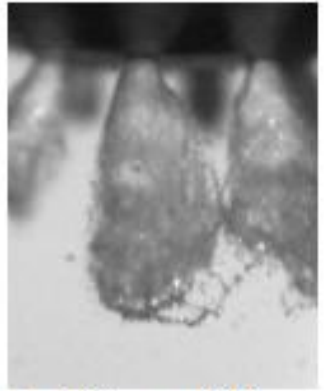

$t=440 \mu \mathrm{s}$ aeSOI

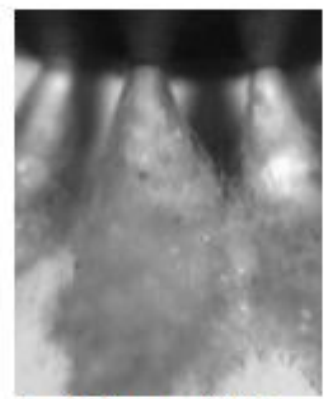

$t=450 \mu \mathrm{s}$ aeSOI

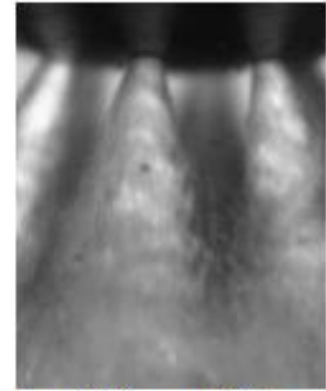

$t=460 \mu \mathrm{s}$ aeSOI

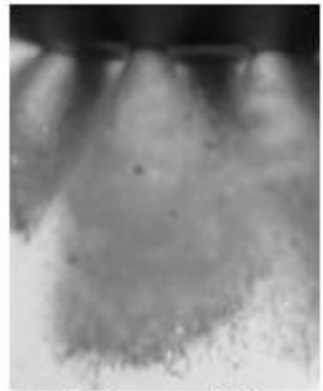

$t=440 \mu \mathrm{s}$ aeSOI

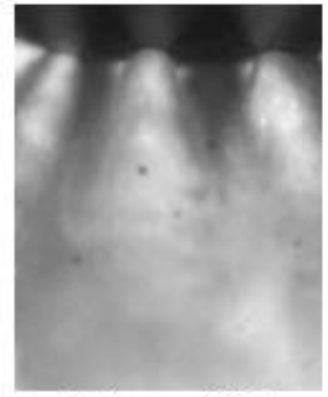

$t=450 \mu \mathrm{s}$ aeSOI

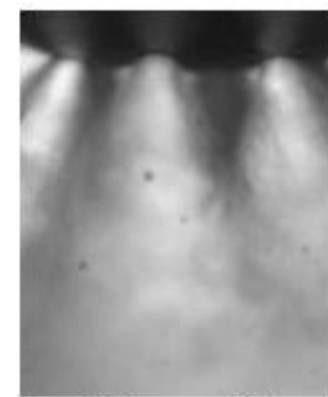

$t=460 \mu \mathrm{s}$ aeSOI

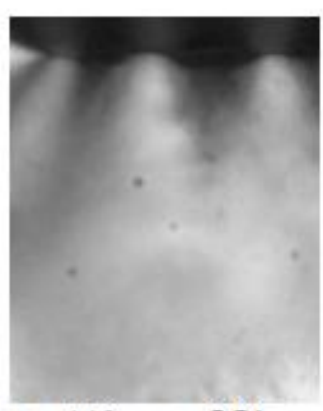

$t=440 \mu \mathrm{s}$ aeSOI

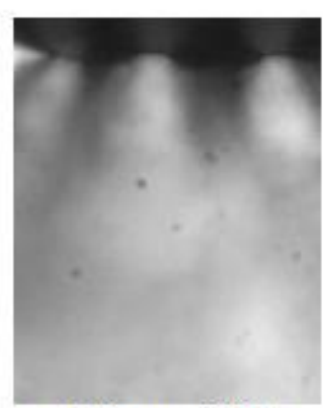

$t=450 \mu \mathrm{s}$ aeSOI

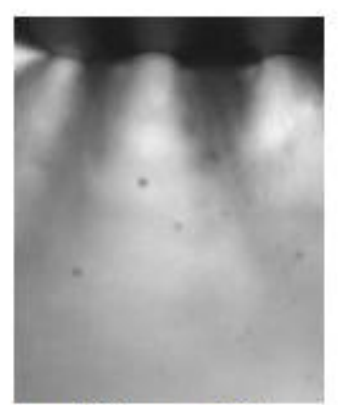

$t=460 \mu \mathrm{s}$ aeSOI

Figure 5-Near field study of the 6-hole injector at different time steps close to the start of the injection event and at a range of temperatures.

Figure 5 illustrates near field results for the $6 \mathrm{H}$ injector across the range of conditions used to understand the level of plume to plume interaction that would be experienced at different engine conditions. From left to right, the chronological images show development of the spray under the same ambient pressure but varying temperatures, whilst the individual rows demonstrate the same test at varying ambient temperature. The temperature was increased by $10 \mathrm{~K}$ steps between tests thus increasing the saturation pressure and SD of the spray given the ambient pressure was fixed across all conditions. There were clear differences in the liquid break up between the different conditions, most notably in terms of the numbers of large droplets and ligaments seen, which were much more prevalent close to the injector at the lowest temperature condition. Increasing the 
temperature and SD resulted in the plume travelling further and having a wider cone angle, leading to greater interaction between neighbouring plumes as the temperature was increased.

The observations made here were attributable to bubble growth and explosion in the liquid fuel when subjected to the conditions inside the pressure vessel. As reported in the work of Guo [33] and Oza [44] the spray breakup could be seen to have been caused by an external breakup regime, whereby the expansion and subsequent explosion of bubbles in the fuel occurs at some distance downstream of the injector hole. This is opposed to the external flash boiling regime reported in literature, where bubbles form in the nozzle and explode immediately on exit, which was not observed here.

In the $460 \mu \mathrm{s}$ cases at $359 \mathrm{~K}$ and $369 \mathrm{~K}$, there was visually such significant overlap of plumes that it was possible for the so called interstitial plumes to form between the main injector plumes [25]. Interstitial plumes represent a phenomenon whereby the interacting region between two neighbouring plumes contains a greater density of fuel than the main plumes themselves, receiving contributions from each of the neighbours. The targeting and penetration length are then changed. These changes can be explained by consideration of the diagram in Figure 6 , which illustrates the momentum vectors of two interacting droplets from neighbouring plumes. The droplets coalesce in this instance with a more downward direction of travel post-collision; this is clearly away from the intended target and it also increases the distance travelled in the vertical direction, increasing the likelihood of piston impaction. This phenomenon was also observed and explored by several researchers. In order to find out the spray overlap (namely interstitial plume formation) mechanism under flash boiling conditions, Guo et al.[33] conducted a number of high speed imaging tests using a single hole injector. It was found out that without plume to plume interaction, a single spray plume would only expand in diameter as it penetrates after exiting the nozzle. They further deduced that for multi-hole injector, with the expansion of the sprays' diameter, they would overlap in space due to plume expansion and hence interaction and coalescence are initiated. This deduction was examined and confirmed in another study conducted by these authors' group [27]. In a study conducted by Wood et al. [45], the relationship between interstitial plume formation and spray penetration distance was investigated. It was found that interstitial plumes were observable only for a limited distance from the injector. This proved that overlapping was the cause of interstitial plumes, as shown in Figure 6 . Because as the spray penetrates further, space between plumes gets bigger and overlapping between plumes could disappear. Interstitial plumes are an indicator of the level of flash boiling that is of importance, since they affect the overall injector-combustion system performance by directing considerable amounts of the fuel away from its intended target and increasing vertical penetration.

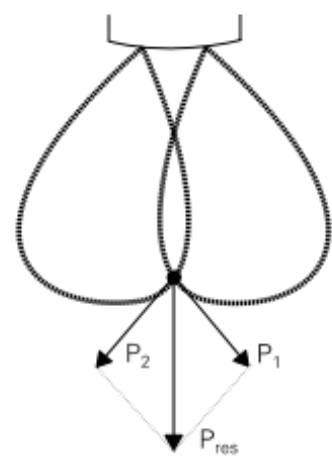

Figure 6 -Sketch illustrating the resultant two-dimensional momentum vector of an abstract droplet collision with the leading edge of a mixing zone of two adjacent plumes. 
The interstitial plume pheonomeom was further explored by capturing images viewing the injector tip from underneath the $6 \mathrm{H}$ injector, coaxial to the injector axis, as presented in

Figure 7 for a range of SD values between $-1.6 \mathrm{~K}$ and $80.2 \mathrm{~K}$. At the slightly negative SD value of -1.6 $\mathrm{K}$, there was no evidence of interaction between the 6 plumes and the primary plumes remain distinct from one another. As the temperature was increased to $359 \mathrm{~K}$, such that the ambient surroundings become a flash boiling condition, the interaction between plumes were first visible. Further increases in temperature, and therefore SD (under constant pressure) increased the amount of interaction and apparent density of the fuel in the interstitial plumes. This leads to the disappearance of the plumes from their intended location during flash boiling and the appearance of a 'starfish' shaped footprint that evidences the interstitial coalescence region between the now missing plumes. This indicates that both boiling (from the plume) and condensation (in the interstitial region) may be occurring since only liquid phase will scatter light to produce these images. 


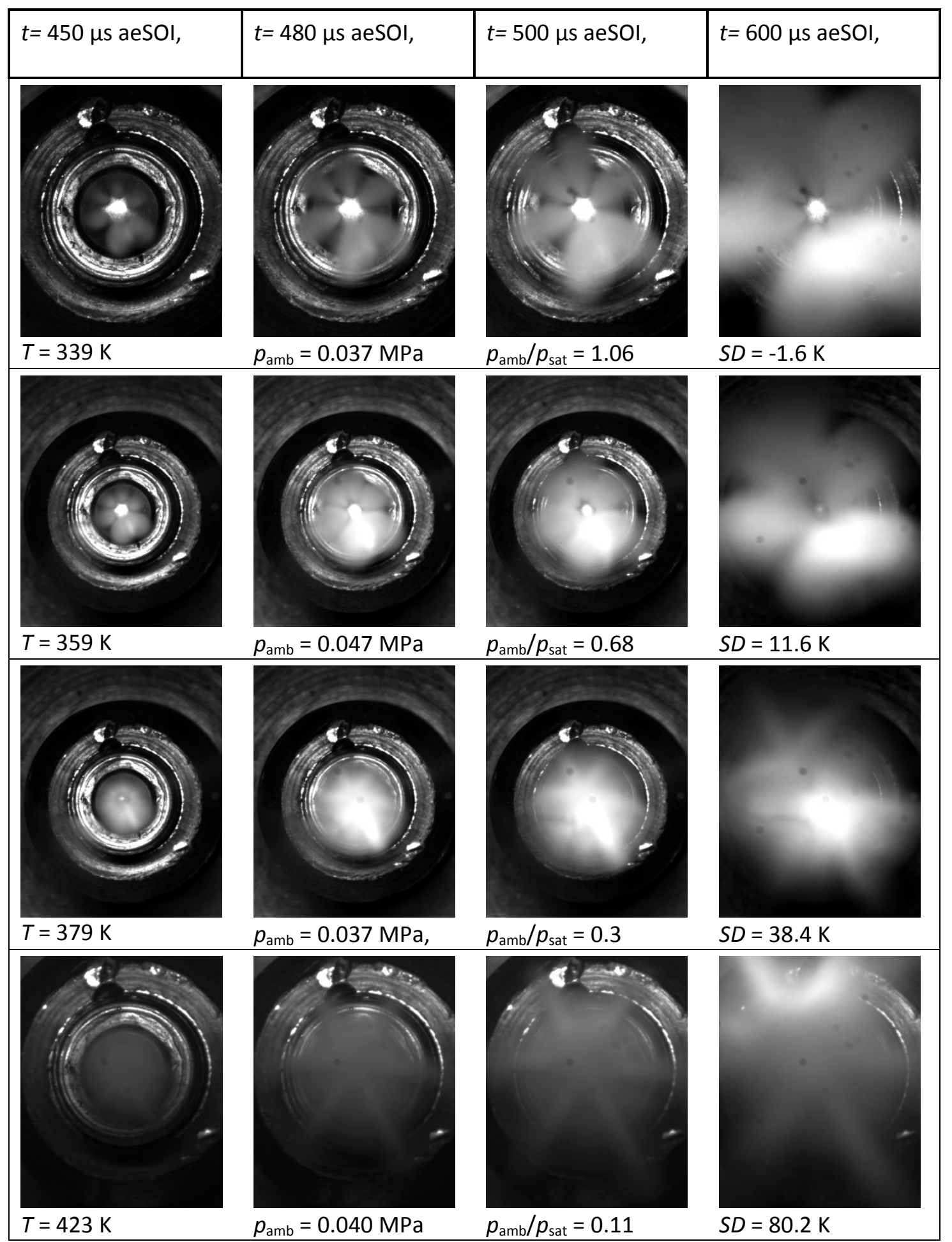

Figure 7 - View of injector tip during injection event of the 6-Hole injector under non-flash boiling and flash-boiling conditions.

A comparison of the $5 \mathrm{H}$ and $6 \mathrm{H}$ injectors' spray patterns at $500 \mu \mathrm{s}$ is presented in Figure 8 illustrating the comparative levels of plume interaction and formation of interstitial plumes for each injector at different SD values. Figure 8a shows a side view and a view from below the injector is presented in Figure $8 b$. 


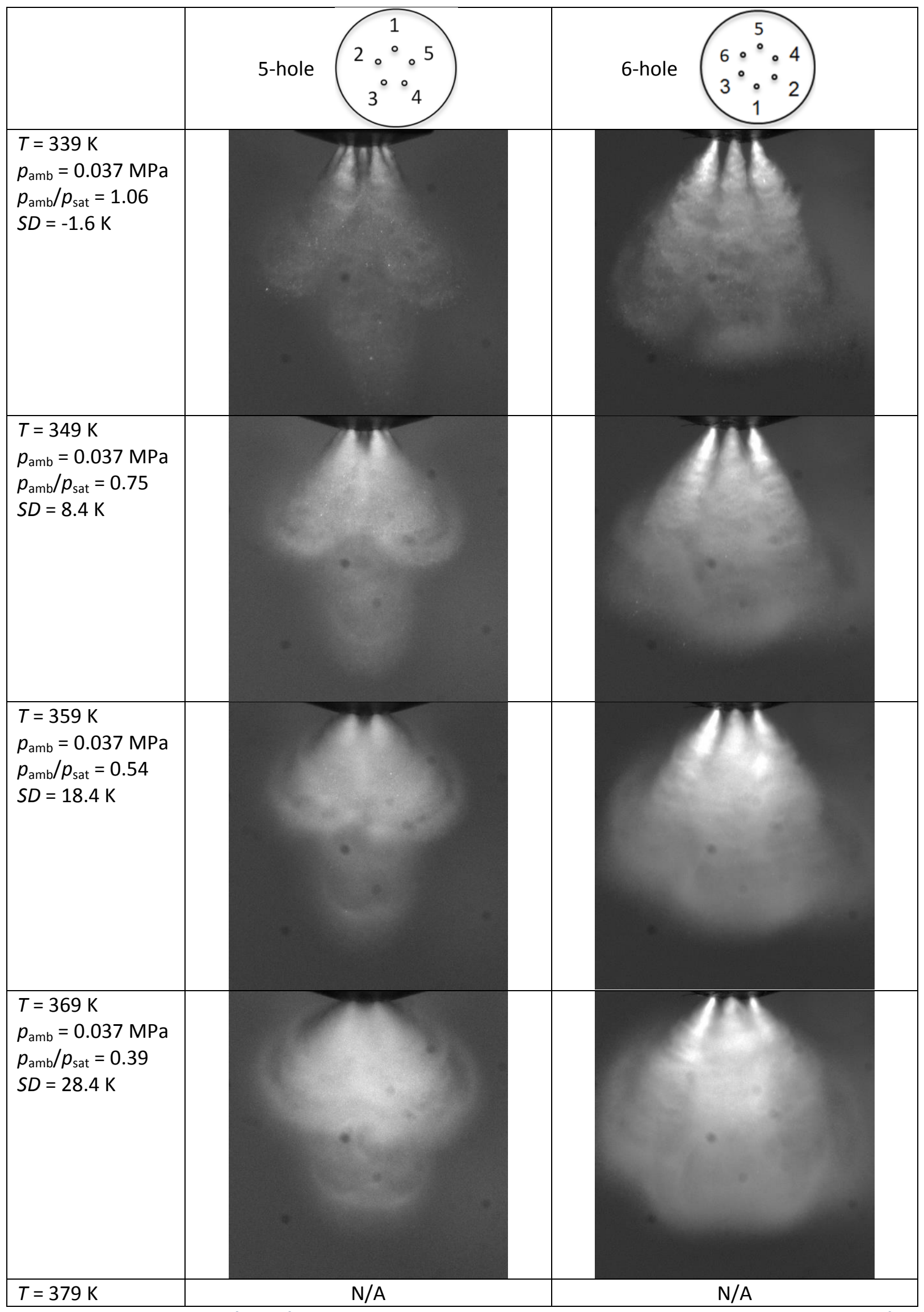

Figure 8a. Comparison of spray for 5-hole and 6-hole injector designs at a $0.037 \mathrm{MPa}$ ambient pressure and range of ambient temperatures. Images captured at 500 us AESOI. (Side View) 


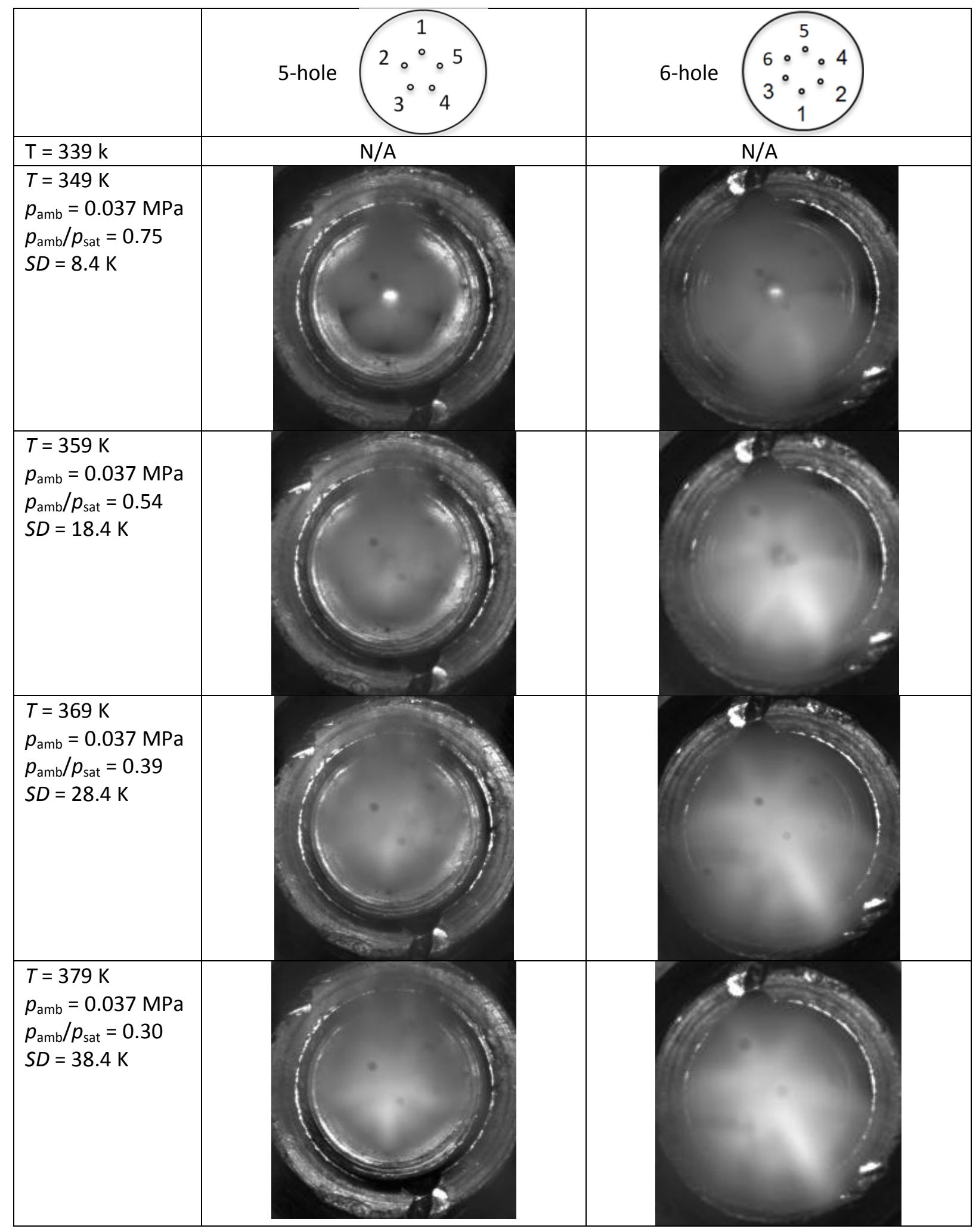

Figure $8 b$-Comparison of spray for 5-hole and 6-hole injector designs at a $0.037 \mathrm{MPa}$ ambient pressure and range of ambient temperatures. Images captured at 500 Ms AESOI. (View along injector axis)

In Figure 8a, with no superheating ( $\mathrm{SD}=-1.6 \mathrm{~K})$, spray plumes from both $5 \mathrm{H}$ and $6 \mathrm{H}$ injectors are well formed and clear boundaries can be seen for the initial plume columns as they emerge from the injector tip. As the SD is increased the individual plumes begin to merge sooner, closer to the injector tip. Due to flash boiling the plumes are expanding at an increased rate. Image quality 
appears to reduce with increasing SD which is partially due to the reduced drop size as they rapidly evaporate but also due to some acceleration causing blurring. This acceleration appears to be within the turbulent velocity field rather than being specifically plume aligned which results in the increased spreading rate. At the $\mathrm{SD}=8.4 \mathrm{~K}$ case, the $5 \mathrm{H}$ injector showed no sign of having formed interstitial plumes, whilst the $6 \mathrm{H}$ injector appeared to exhibit some signs of partial coalescence of adjacent plumes, most notably between plumes 1 and plume 2, witnessed in Figure $8 \mathrm{~b}$. As the SD value was increased; it was only from $\mathrm{SD}=38.4$ that the $5 \mathrm{H}$ injector began to exhibit clear appearance of interstitial plumes forming, whereas the $6 \mathrm{H}$ injector was exhibiting the clear appearance of interstitial plumes from SD=18.4 K. This can be seen in the last two images in Figure $8 \mathrm{~b}$ as a 5 -limbed and 6-limbed starfish shaped white region from the scattered light from the spray in these regions. The $5 \mathrm{H}$ injector at the two mid-values of SD does not show clearly formed individual plumes, with their boundaries less well defined, but it is only the highest SD value shown where interstitial regions have begun to be formed as seen from below. In the side view the interstitial plumes are less obvious though some bright/dark axial streaking can perhaps be seen for the $6 \mathrm{H}$ injector.

The results indicated that the $5 \mathrm{H}$ design offered greater resistance towards the coalescence of plumes and would therefore be likely to better resist collapse and maintain its intended fuel targeting and penetration over a wider engine operating range. This is due to both the larger spacing between holes as well as a larger mass flow rate in each plume, requiring a greater amount of heat to be absorbed to grow bubbles to the point of explosion.

\subsection{In cylinder observations and measurements}

The results of the spray characterisation rig imaging tests presented previously showed that the $5 \mathrm{H}$ injector was more resistant to spray collapse under flash boiling conditions than the $6 \mathrm{H}$ injector. Resistance to spray collapse is a desirable feature of an injector design, which must function under a wide range of constantly varying in-cylinder conditions. Boroscopic imaging of the fuel sprays from each injector in the engine, confirmed this observation under real operating conditions and compared with the engine performance data. Tests of the two injectors were conducted at 4 different start of injection (SOI) timings ranging from early to late of the calibrated SOI time. During all tests, the engine was controlled to a speed of $3000 \mathrm{rpm}$ and load of $85 \mathrm{Nm}$, with a fixed spark timing of $12^{\circ}$ BTDC.

Figure 9 presents the apparent heat release rate (calculated from in-cylinder pressure) when operated with each of the two injectors, calculated from the measured cylinder pressure and plotted against the engine crank angle rotation after ignition. When injecting at the calibrated SOI time of $280^{\circ}$ BTDC, the heat release rate of each could be seen to be very similar. When injecting at SOls other than the calibrated angle, the $5 \mathrm{H}$ injector maintained a similar heat release profile and peak value in all but the latest injection case where an approximately $8 \%$ reduction was observed, whilst the $6 \mathrm{H}$ injector demonstrated a reduction in peak heat release rate for all timings away from the calibrated value. The fact that the combustion of the $5 \mathrm{H}$ injector was always faster than for the $6 \mathrm{H}$ indicated that the difference between the air-fuel mixtures of each case were significant enough to affect the combustion process.

Figure 10 shows the brake specific $\mathrm{NO}_{\mathrm{x}}\left(\mathrm{BSNO}_{\mathrm{x}}\right)$ and brake specific fuel consumption (BSFC) of the two injectors across the tested conditions. It can be seen that the $\mathrm{NO}_{x}$ emissions of the $5 \mathrm{H}$ injector were consistently higher than the $6 \mathrm{H}$ injector across the range of $\mathrm{SOI}$, which supported the previous observation that the combustion of the $5 \mathrm{H}$ injector was faster at three of the four SOI times. The faster combustion would be accompanied by a higher peak combustion temperature which is associated with NOx production, due to the high energy requirement of NOx forming dissociation reactions. 
The difference between BSFC with each of the two injectors was less than $3 \%$, as shown in Figure 10; this was within the measurement error range and thus the impact of injector design on BSFC was not considered significant.
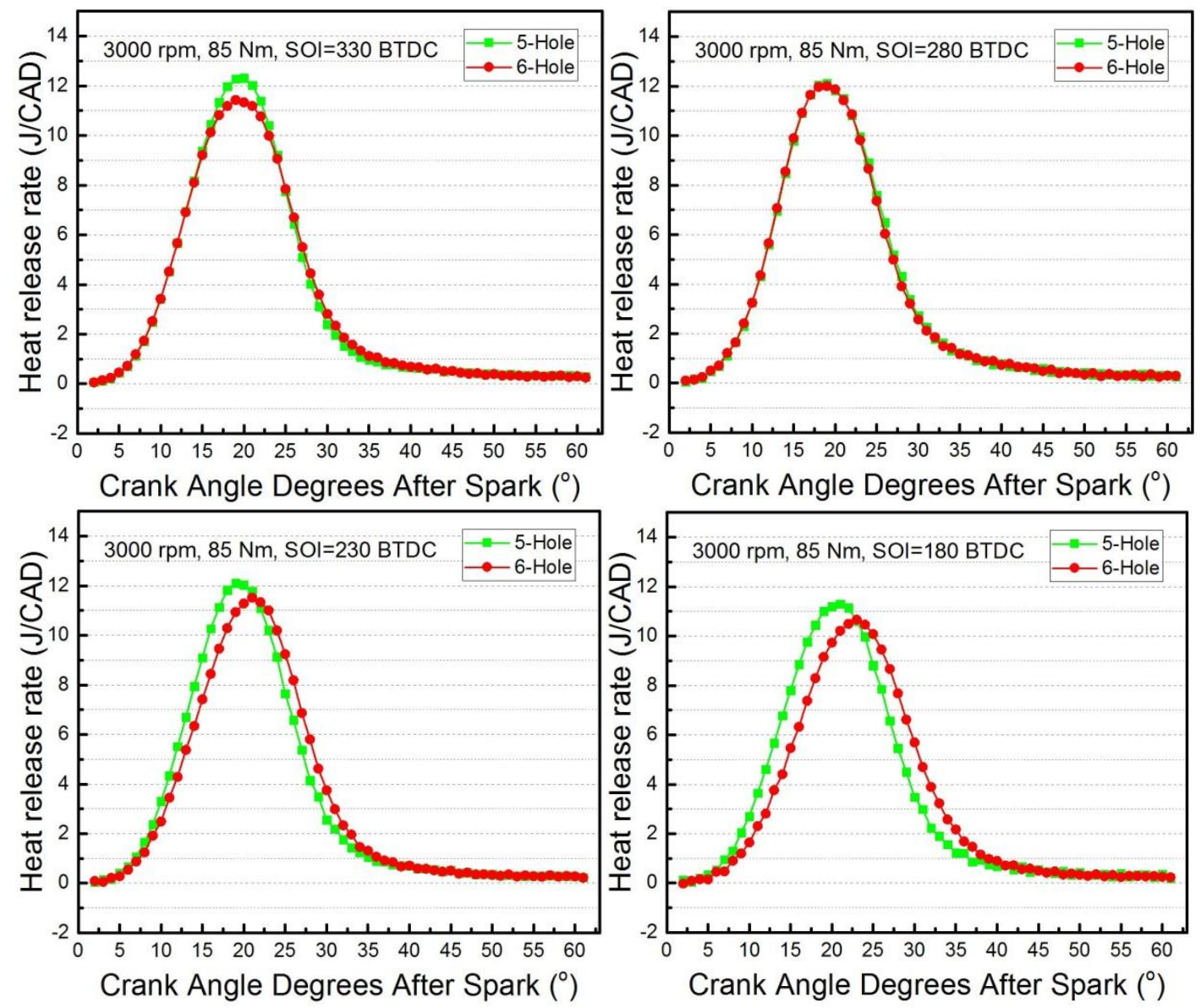

Figure 9-Apparent heat release rate curves of the $5 \mathrm{H}$ and $6 \mathrm{H}$ injectors at different SOIs.
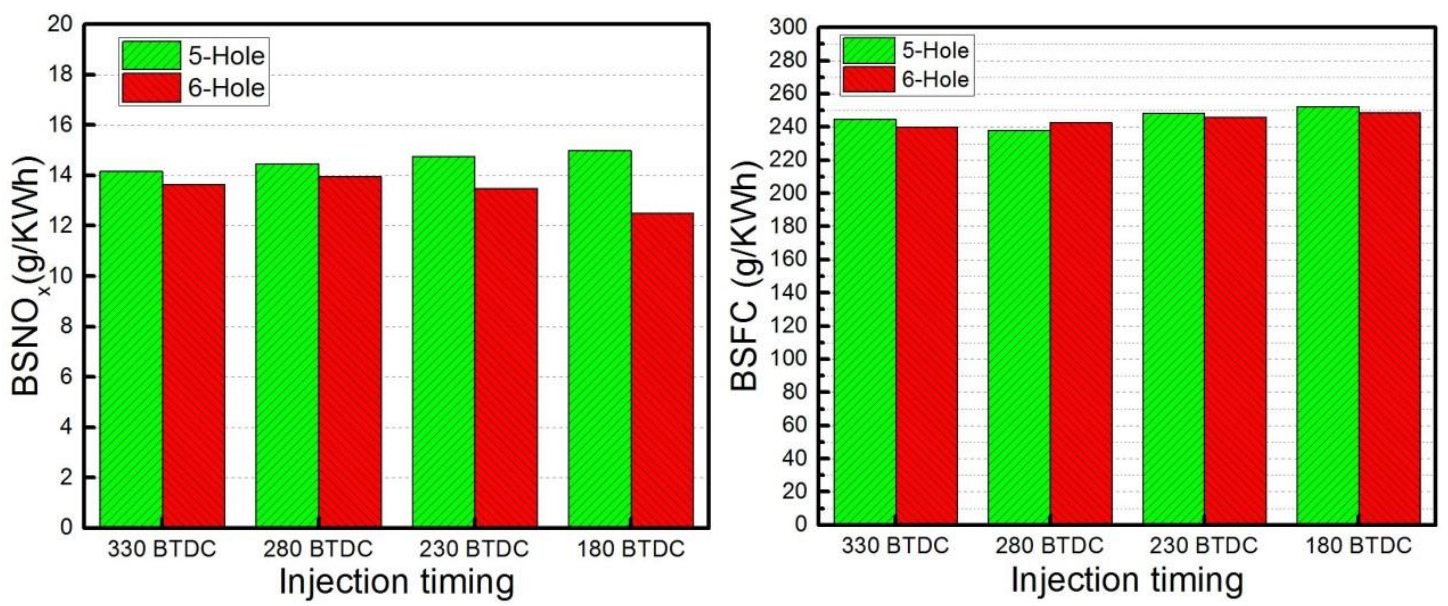

Figure 10 - Brake specific NOx and Brake specific fuel consumption for two injectors under different SOls. 


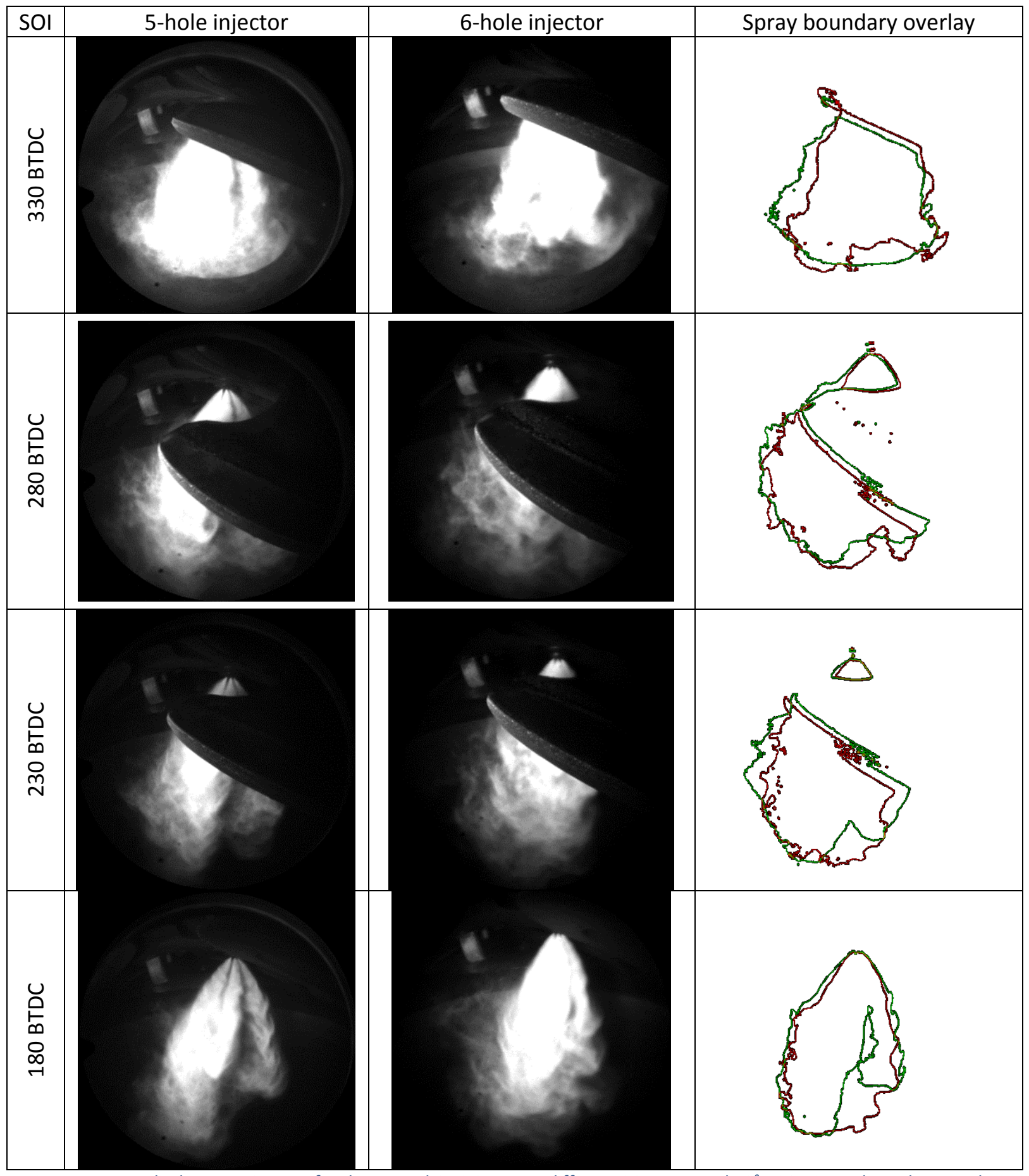

Figure 11 - In-cylinder spray images for the $5 \mathrm{H}$ and $6 \mathrm{H}$ injector at different $\mathrm{SOI}$, captured $10^{\circ} \mathrm{ASOI}$, Spray boundary overlay: 5-Hole Green; 6-Hole Red.

Figure 11 shows in-cylinder images of the fuel sprays from each of the injectors captured at $10^{\circ}$ ASOI during the engine operation. From the direct, overlaid comparison of spray boundaries, it is apparent that both injector's spray morphologies were affected by the SOI timing and both behaved differently to one another at a given $\mathrm{SOI}$ time. The $5 \mathrm{H}$ injector appeared to maintain its morphology better than the $6 \mathrm{H}$ injector across the timing range, exhibiting distinct plume separation in the images at the three later injection timings tested whilst the $6 \mathrm{H}$ appeared to show a plume structure that had merged and, in some cases collapsed inward (180 BTDC SOI). These in-cylinder observations agreed with the findings of the back-lit imaging study on the spray characterisation rig 
presented previously, in that the $5 \mathrm{H}$ injector seemed to maintain its intended spray morphology better under flash boiling conditions.

Combustion images taken at $30^{\circ}$ ATDC of the combustion for $5 \mathrm{H}$ and $6 \mathrm{H}$ injectors at different $\mathrm{SOI}$ are shown in Figure 12. The images suggest that the combustion in the $6 \mathrm{H}$ injector case was affected more by the $\mathrm{SOI}$ time than the $5 \mathrm{H}$ injector. This is evidenced by the greater variation in the level of diffusion burning captured in the cylinder between SOI times. At the calibrated SOI of $280^{\circ}$ BTDC and the next position later at $230^{\circ} \mathrm{BTDC}$, the combustion appears to be premixed in nature. However, further away from the calibrated time the combustion appears significantly sooty, indicating diffusive combustion. These regions of diffusive combustion would be likely to lead to increased emission of particulates.

The location of the diffusive combustion seen in the early injection case of the $6 \mathrm{H}$ injector on the piston crown was attributable to piston impaction, due to the higher penetration length of the $6 \mathrm{H}$ injector. This agrees with measurements on the spray characterisation rig and the apparent collapse of the spray seen during in-engine spray imaging. The combustion using the $5 \mathrm{H}$ injector appeared much cleaner at this SOI, suggesting a lower level of impaction, which would be supported by the shorter measured penetration length of the $5 \mathrm{H}$ injector and the wider angle of spray seen in-engine.

At the latest injection timing, $180^{\circ}$ BTDC there is again a significant difference between the appearance of the $5 \mathrm{H}$ and $6 \mathrm{H}$ in-cylinder images. The $5 \mathrm{H}$ result indicates predominantly premixed combustion, with little evidence of burning soot regions, except for one small area close to the centre of the image. The image of $6 \mathrm{H}$ injector's combustion shows widespread diffusive combustion around the cylinder, which is due to the lack of time for proper mixing of fuel and air prior to ignition. The fact that the $5 \mathrm{H}$ injector appears to exhibit better fuel-air mixing (evident from cleaner combustion) supported both the engine and rig spray imaging, which shows the wider cone angle of the $5 \mathrm{H}$ injector and therefore likely utilising the air charge more fully for mixing. 


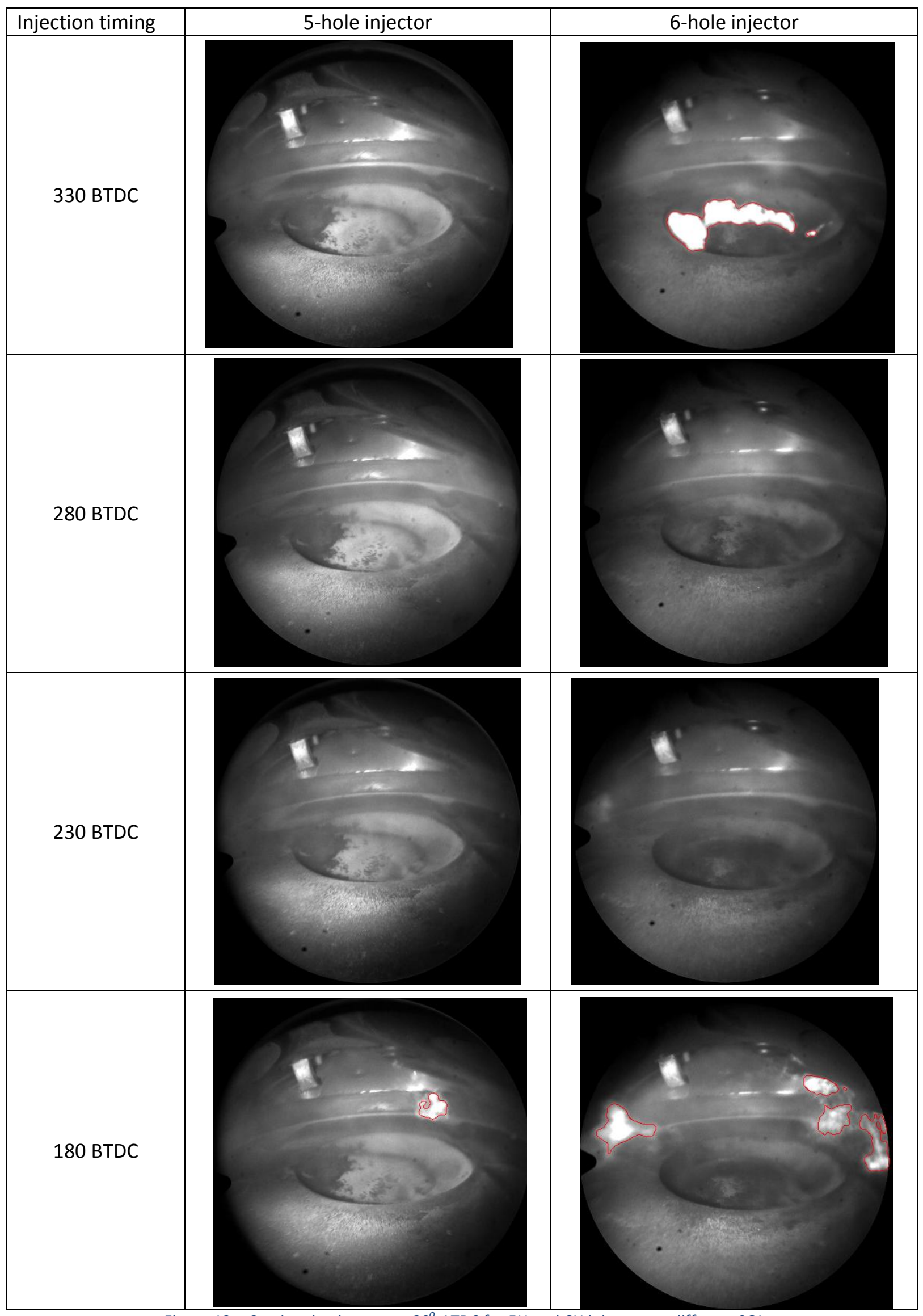

Figure 12 - Combustion images at $30^{\circ}$ ATDC for $5 \mathrm{H}$ and $6 \mathrm{H}$ injectors at different $\mathrm{SOI}$

(observed diffusion flame highlighted in red). 
The engine particulate emissions of the two candidate injectors, also measured during the tests across a range of injection timings are compared in Figure 13 and Figure 14. It can be seen in Figure 13 that the total particulate number concentration measured during the tests of each injector was comparable at the calibrated injection timing of $280^{\circ}$ BTDC, but significantly higher for the $6 \mathrm{H}$ injection at any other timing, up to 100 times greater for the earliest injection case. This corroborates the imaging result of Figure 12. This difference suggested that the $6 \mathrm{H}$ injector was more sensitive to injection timing and would have a much narrower acceptable injection timing range.

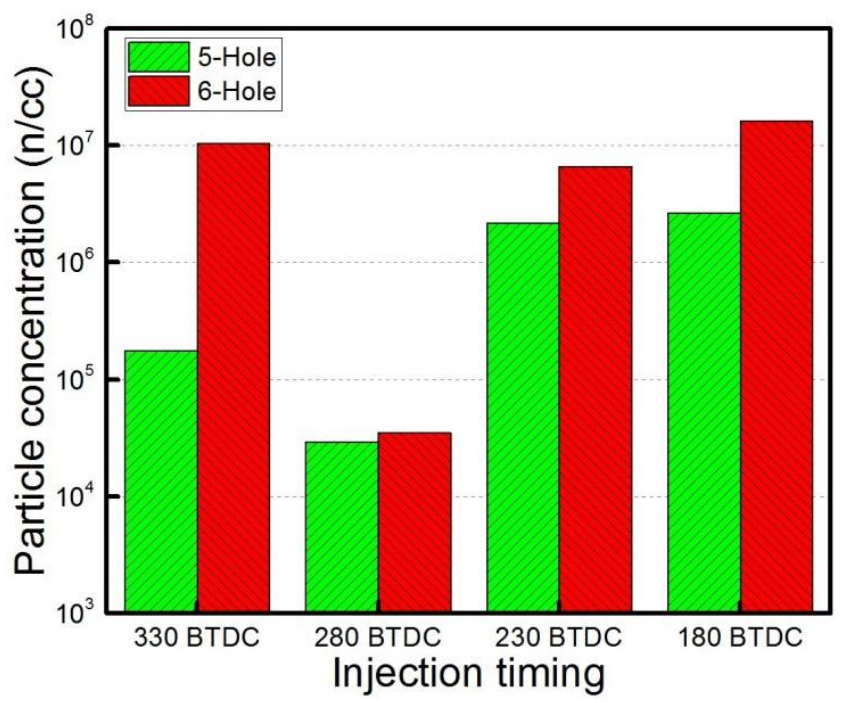

Figure 13 - Total Particulate Number (PN) emissions for the 5H and 6H injectors with the engine operating 3000 rpm, 85 $\mathrm{Nm}$ load and a range of injection timings.

Figure 14 shows the PN size distribution of the two injectors at the four injection SOI angles tested, further demonstrating the increased sensitivity of the 6-hole injector to injection timing. In the case of the calibration point, $280^{\circ}$ BTDC, a similar distribution of PN size is observed. This is to be expected at the calibration point for which the injectors have been optimised. Note this graph scale for the calibration SOI is different to the other 3 SOls, with a peak dN/dlogDp of $1 \times 10^{5} \mathrm{n} / \mathrm{cm}^{3}$ compared to $1 \times 10^{7} \mathrm{n} / \mathrm{cm}^{3}$.

With early injection timing of $330^{\circ} \mathrm{BTDC}$, it was the $6 \mathrm{H}$ injector which showed a strong diffusion flame on the piston crown in Figure 12, where none was evident for the $5 \mathrm{H}$ injector. Both injectors are expected to be in flash boiling mode at this condition but the $6 \mathrm{H}$ injector shows slightly higher vertical penetration and spray appears to be impinging on the piston crown in the bowl region. This allows a pool fire to form and is the cause of $\sim 350$ fold increase in peak PN count at $100 \mathrm{~nm}$ compared to $280^{\circ}$ BTDC SOI.

At the later injection timing of $230^{\circ}$ BTDC, diffusion flames are not evident for either injector, but a significant increase in PN, particularly for the smaller sizes is seen. The reduced time for air-fuel mixing is the predominant reason for the increase in nucleation mode particulate count which is consistent with these smaller particulate sizes. With the latest injection timing of $180^{\circ}$ BTDC the PN rises again for the $6 \mathrm{H}$ injector at the larger particulate sizes. This is consistent with the large regions of diffusion flame evident in Figure 12 around much of the piston crevice region. While also evident for the $5 \mathrm{H}$ injector it is a small region in comparison, only occasionally occurring. As a result, it does not modify the PN significantly. 

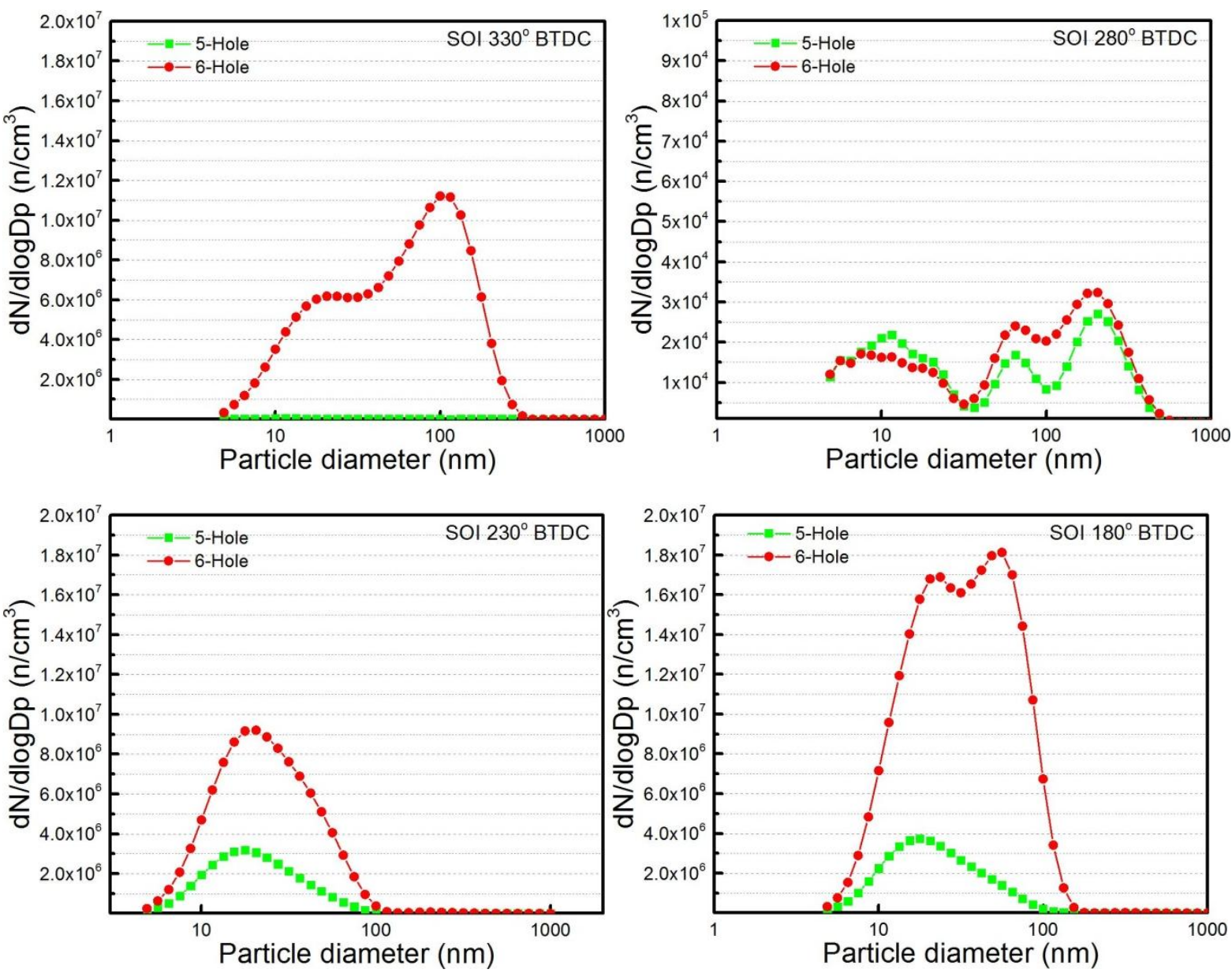

Figure 14 - Particulate Number size distributions for $5 \mathrm{H}$ and $6 \mathrm{H}$ injectors with the engine operating at $3000 \mathrm{rpm}, 85 \mathrm{Nm}$ load and a range of injection timings.

\section{Conclusion}

In this study, a 5-hole $(5 \mathrm{H})$ and a 6 -hole $(6 \mathrm{H})$ injector designed for the same 3-cylinder 1 litre GTDI engine application were tested against one another to determine engine performance, $\mathrm{NO}_{\mathrm{x}}$ and particulate emissions. The comparison was made by a combination of imaging of the injector's fuel spray both on a spray characterisation rig under simulated engine conditions and on an endoscopically accessed engine, where combustion was also imaged and emissions performance measured. The insight and understanding of the spray morphology and plume interaction gathered from the rig imaging was then able to be combined with the measurements of actual engine performance.

The following key conclusions were drawn from this work:

1. The $5 \mathrm{H}$ and $6 \mathrm{H}$ injectors exhibited differences in engine performance when tested, which must be attributable to their macroscopic spray characteristics, since they had similar droplet diameters and droplet size distributions.

2. Interaction between spray plumes led to the appearance of interstitial plumes, containing a greater quantity of liquid fuel than the primary plumes themselves. The $5 \mathrm{H}$ injector was more tolerant to this phenomenon, maintaining its primary plume structure to a higher SD than the $6 \mathrm{H}$ design. This was attributable to its greater flow rate per hole as well as the larger hole separation. 
3. Due to less plume to plume interaction, the $5 \mathrm{H}$ injector had more resistance towards spray collapse than the $6 \mathrm{H}$. It better maintained its spray morphology and had a shorter penetration length under flash boiling conditions.

4. The $5 \mathrm{H}$ injector created a wider spray cone than the $6 \mathrm{H}$ injector under all SOI times tested, leading to a better air-fuel mixture and thus less diffusive combustion. The better mixing of the $5 \mathrm{H}$ injector led to faster combustion and therefore higher $\mathrm{NO}_{x}$ emissions because of the higher peak combustion temperatures.

5. The PN emissions were lower for the $5 \mathrm{H}$ injector across all SOI times, due to the better mixing. In addition, they were less sensitive to changes in $\mathrm{SOI}$ than the $6 \mathrm{H}$ injector because of the $5 \mathrm{H}$ injector's ability to maintain its spray morphology under flash boiling conditions.

6. A small difference was seen in NOx with the $6 \mathrm{H}$ injector having lower values by typically around $5 \%$ percent because poorer mixing led to slower combustion rate and lower peak temperatures. This difference increased away from the engine calibration timings.

\section{Acknowledgements}

The authors would like to acknowledge the financial support of the Advanced Propulsion Centre (APC) for this work which was undertaken as part of TSB/APC project number 113130 . The authors also wish to acknowledge Ford Motor Company for their technical support of the work. The authors would also like to thank Richard Gerber for his work on the spray characterisation rig experiments.

\section{References}

[1] Johnson T, Joshi A. Review of Vehicle Engine Efficiency and Emissions. SAE Int J Engines 2018;11:1307-30. doi:10.4271/2018-01-0329.

[2] Hannan MA, Azidin FA, Mohamed A. Hybrid electric vehicles and their challenges: A review. Renew Sustain Energy Rev 2014;29:135-50. doi:10.1016/j.rser.2013.08.097.

[3] Peterson SB, Whitacre JF, Apt J. The economics of using plug-in hybrid electric vehicle battery packs for grid storage. J Power Sources 2010;195:2377-84.

doi:10.1016/j.jpowsour.2009.09.070.

[4] Morita K. Automotive power source in 21st century. JSAE Rev 2003;24:3-7. doi:10.1016/S0389-4304(02)00250-3.

[5] Leduc P, Dubar B, Ranini A, Monnier G. Downsizing of gasoline engine: An efficient way to reduce CO2 emissions. Oil Gas Sci Technol 2003;58:115-27. doi:10.2516/ogst:2003008.

[6] Bahreini R, Xue J, Johnson K, Durbin T, Quiros D, Hu S, et al. Characterizing emissions and optical properties of particulate matter from PFI and GDI light-duty gasoline vehicles. J Aerosol Sci 2015. doi:10.1016/j.jaerosci.2015.08.011.

[7] Zhao H. Advanced direct injection combustion engine technologies and development. Elsevier 2010. doi:10.1533/9781845697457.

[8] Zhu R, Hu J, Bao X, He L, Lai Y, Zu L, et al. Tailpipe emissions from gasoline direct injection (GDI) and port fuel injection (PFI) vehicles at both low and high ambient temperatures. Environ Pollut 2016. doi:10.1016/j.envpol.2016.05.066.

[9] Qian Y, Li Z, Yu L, Wang X, Lu X. Review of the state-of-the-art of particulate matter emissions from modern gasoline fueled engines. Appl Energy 2019;238:1269-98. doi:10.1016/j.apenergy.2019.01.179.

[10] Wu S, Xu M, Hung DLS, Li T, Pan H. Near-nozzle spray and spray collapse characteristics of 
spark-ignition direct-injection fuel injectors under sub-cooled and superheated conditions. Fuel 2016;183:322-34. doi:10.1016/j.fuel.2016.06.080.

[11] Guo H, Ma X, Li Y, Liang S, Wang Z, Xu H, et al. Effect of flash boiling on microscopic and macroscopic spray characteristics in optical GDI engine. Fuel 2017;190:79-89. doi:10.1016/j.fuel.2016.11.043.

[12] Sher E, Bar-Kohany T, Rashkovan A. Flash-boiling atomization. Prog Energy Combust Sci 2008;34:417-39. doi:10.1016/j.pecs.2007.05.001.

[13] Reitz RD. A photographic study of flash-boiling atomization. Aerosol Sci Technol 1990. doi:10.1080/02786829008959370.

[14] Jiang C, Xu H, Srivastava D, Ma X, Dearn K, Cracknell R, et al. Effect of fuel injector deposit on spray characteristics, gaseous emissions and particulate matter in a gasoline direct injection engine. Appl Energy 2017;203:390-402. doi:10.1016/j.apenergy.2017.06.020.

[15] Badawy T, Attar MA, Hutchins P, Xu H, Krueger Venus J, Cracknell R. Investigation of injector coking effects on spray characteristic and engine performance in gasoline direct injection engines. Appl Energy 2018;220:375-94. doi:10.1016/j.apenergy.2018.03.133.

[16] Badawy T, Attar MA, Xu H, Ghafourian A. Assessment of gasoline direct injector fouling effects on fuel injection, engine performance and emissions. Appl Energy 2018;220:351-74. doi:10.1016/j.apenergy.2018.03.032.

[17] Bonatesta F, Chiappetta E, La Rocca A. Part-load particulate matter from a GDI engine and the connection with combustion characteristics. Appl Energy 2014;124:366-76.

doi:10.1016/j.apenergy.2014.03.030.

[18] Wang B, Mosbach S, Schmutzhard S, Shuai S, Huang Y, Kraft M. Modelling soot formation from wall films in a gasoline direct injection engine using a detailed population balance model. Appl Energy 2016;163:154-66. doi:10.1016/j.apenergy.2015.11.011.

[19] Khan MM, Hélie J, Gorokhovski M, Sheikh NA. Experimental and numerical study of flash boiling in gasoline direct injection sprays. Appl Therm Eng 2017;123:377-89. doi:10.1016/j.applthermaleng.2017.05.102.

[20] Pachiannan T, Zhong W, Rajkumar S, He Z, Leng X, Wang Q. A literature review of fuel effects on performance and emission characteristics of low-temperature combustion strategies. Appl Energy 2019;251:113380. doi:10.1016/j.apenergy.2019.113380.

[21] Hergueta C, Tsolakis A, Herreros JM, Bogarra M, Price E, Simmance K, et al. Impact of bioalcohol fuels combustion on particulate matter morphology from efficient gasoline direct injection engines. Appl Energy 2018;230:794-802. doi:10.1016/j.apenergy.2018.08.076.

[22] Jiang C, Parker MC, Spencer A, Wigley G, Garner CP, Helie J. Droplet Size Development in a DISI Injector Fuel Spray. Proc. 18th Int. Symp. Appl. Laser Imaging Tech. to Fluid Mech., 2016.

[23] Krämer M, Kull E, Heldmann M, Wensing M. Investigations on Gasoline Spray Propagation Behaviour Characteristic for Multihole Injectors. SAE Tech Pap 2014-01-2732 2014. doi:10.4271/2014-01-2732.Copyright.

[24] Krämer M, Kull E, Wensing M. Flashboiling-induced targeting changes in gasoline direct injection sprays. Int J Engine Res 2016;17:97-107. doi:10.1177/1468087415604763. 
[25] Mojtabi M, Wigley G, Helie J. The effect of flash boiling on the atomization performance of gasoline direct injection multistream injectors. At Sprays 2014;24:467-93.

doi:10.1615/AtomizSpr.2014008296.

[26] Li Y, Guo H, Ma X, Qi Y, Wang Z, Xu H, et al. Morphology analysis on multi-jet flash-boiling sprays under wide ambient pressures. Fuel 2018;211:38-47. doi:10.1016/j.fuel.2017.08.082.

[27] Li Y, Guo H, Fei S, Ma X, Zhang Z, Chen L, et al. An exploration on collapse mechanism of multi-jet flash-boiling sprays. Appl Therm Eng 2018;134:20-8.

doi:10.1016/j.applthermaleng.2018.01.102.

[28] Schulz F, Beyrau F. The influence of flash-boiling on spray-targeting and fuel film formation. Fuel 2017;208:587-94. doi:10.1016/j.fuel.2017.07.047.

[29] Chin ST, Lee CFF. Numerical investigation of the effect of wall wetting on hydrocarbon emissions in engines. Proc Combust Inst 2002;29:767-73. doi:10.1016/S1540-7489(02)800980.

[30] Serras-Pereira J, Aleiferis PG, Richardson D. Imaging and heat flux measurements of wall impinging sprays of hydrocarbons and alcohols in a direct-injection spark-ignition engine. Fuel 2012;91:264-97. doi:10.1016/j.fuel.2011.07.037.

[31] Levy M, Levy $Y$, Sher E. Spray structure as generated under homogeneous flash boiling nucleation regime. Appl Therm Eng 2014;73:414-21.

doi:10.1016/j.applthermaleng.2014.08.008.

[32] Zeng W, Xu M, Zhang G, Zhang Y, Cleary DJ. Atomization and vaporization for flash-boiling multi-hole sprays with alcohol fuels. Fuel 2012;95:287-97. doi:10.1016/j.fuel.2011.08.048.

[33] Guo H, Wang B, Li Y, Xu H, Wu Z. Characterizing external flashing jet from single-hole GDI injector. Int J Heat Mass Transf 2018;121:924-32.

doi:10.1016/j.ijheatmasstransfer.2018.01.042.

[34] Wu S, Xu M, Hung DLS, Pan $\mathrm{H}$. Effects of nozzle configuration on internal flow and primary jet breakup of flash boiling fuel sprays. Int J Heat Mass Transf 2017;110:730-8.

doi:10.1016/j.ijheatmasstransfer.2017.03.073.

[35] Wu S, Xu M, Hung DLS, Pan H. In-nozzle flow investigation of flash boiling fuel sprays. Appl Therm Eng 2017;117:644-51. doi:10.1016/j.applthermaleng.2016.12.105.

[36] Wang B, Wang Z, Bao X, Li Y, Jiang Y, Xu H, et al. Microscopic investigation of near-field spray characteristics of 2-methylfuran, ethanol and isooctane under flash boiling conditions. Fuel 2018;215:142-52. doi:10.1016/j.fuel.2017.10.035.

[37] Guo H, Ding H, Li Y, Ma X, Wang Z, Xu H, et al. Comparison of spray collapses at elevated ambient pressure and flash boiling conditions using multi-hole gasoline direct injector. Fuel 2017;199:125-34. doi:10.1016/j.fuel.2017.02.071.

[38] Khan MM, Hélie J, Gorokhovski M, Sheikh NA. Experimental and numerical study of flash boiling in gasoline direct injection sprays. Appl Therm Eng 2017;123:377-89.

doi:10.1016/j.applthermaleng.2017.05.102.

[39] Chan QN, Bao Y, Kook S. Effects of injection pressure on the structural transformation of flash-boiling sprays of gasoline and ethanol in a spark-ignition direct-injection (SIDI) engine. Fuel 2014;130:228-40. doi:10.1016/j.fuel.2014.04.015. 
[40] Wang Z, Jiang C, Xu H, Wyszynski ML. Macroscopic and microscopic characterization of diesel spray under room temperature and low temperature with split injection. Fuel Process Technol 2016;142. doi:10.1016/j.fuproc.2015.10.007.

[41] Wang Z, Xu H, Jiang C, Wyszynski MLW. Experimental study on microscopic and macroscopic characteristics of diesel spray with split injection. Fuel 2016;174. doi:10.1016/j.fuel.2016.01.083.

[42] Wigley G, Hargrave GK, Heath J. A High Power, High Resolution LDA/PDA System Applied to Gasoline Direct Injection Sprays. Part Part Syst Charact 1999;16:11-9. doi:10.1002/(SICI)15214117(199905)16:1<11::AID-PPSC11>3.0.CO;2-I.

[43] Jiang C, Parker MC, Helie J, Spencer A, Garner CP, Wigley G. Impact of gasoline direct injection fuel injector hole geometry on spray characteristics under flash boiling and ambient conditions. Fuel 2019:71-82. doi:10.1016/j.fuel.2018.11.143.

[44] Oza RD, Sinnamon JF. An Experimental and Analytical Study of Flash-Boiling Fuel Injection 1983. SAE transactions, pp.948-962. doi:10.4271/830590.

[45] Wood A, Wigley G, Helie J. Flash Boiling Sprays produced by a 6-hole GDI Injector 2014; In 17th International Symposium on Applications of Laser Techniques to Fluid Mechanics (pp. 710). doi:10.13140/2.1.5105.3445. 